\title{
A Study of a Desensitizing Dentifrice and Cervical Hypersensitivity
}

\author{
BY B. A. SMITH, D.D.s., M.s. * AND M. M. ASH, JR., D.D.s., M.s.**
}

$\mathrm{N}^{2}$ UMEROUS investigators have reported on the effectiveness of various agents for the control of hypersensitivity $4,5,7,9,10,12,15,18,20,21,23$ and also on pain transmission in teeth. $2,6,13$, $16,17,19,25$ Only a few investigators have reported findings relative to the evaluation of dentifrices marketed for the control of hypersensitivity of the surfaces of the roots of the teeth. $1,8,11,14,24,26,28$ According to the manufacturers' claims and to reports in the literature, two widely marketed dentifrices have therapeutic value for control of hypersensitivity of the teeth. The Council on Dental Therapeutics has not accepted either of these dentifrices because of the lack of conclusive evidence of their therapeutic value. The object of this study was to determine the therapeutic effectiveness of Sensodyne, under conditions of a double-blind procedure and controlled application of quantitative stimuli.

\section{METHODS AND MATERIALS}

Prior methods of evaluation of the effectiveness of dentifrices have been based on a subject's impression of changes in sensitivity to: (1) qualitative experimental stimuli such as the passage of an explorer tip over the root surface, a blast of cold air directed on the root surface, scaling and polishing procedures, or a cold water rinse; or to (2) naturally occurring stimuli such as hot or cold foods and drinks, acid containing foods and drinks, sweets, or toothbrushing procedures. None of these methods precisely quantitates the applied stimuli. Attempts have been made to

*Instructor in Periodontics, The University of Michigan School of Dentistry, Ann Arbor, Michigan.

* Professor of Dentistry, The University of Michigan School of Dentistry, Ann Arbor, Michigan. quantitate chemical stimulus, ${ }^{2,17}$ to standardize mechanical stimuli, ${ }^{3}$ and to utilize various devices for the production, deliverance, and measurement of controlled thermal stimuli. ${ }^{22,27}$ None of these methods for controlled measurement of stimuli has been used for evaluation of cervical sensitivity of teeth. A review of these methods indicates that with the exception of the thermo-electric tooth stimulator, ${ }^{22}$ all have limited use for testing cervical hypersensitivity.

The most practical method of producing and measuring controlled thermal stimuli has been reported by Naylor ${ }^{22}$ who developed a thermo-electric tooth stimulator based on the principle of thermo-electric cooling. The device is capable of providing "accurately controlled stimuli to the teeth at temperatures below $0^{\circ} \mathrm{C}$." A modified form of this device was made for use in the present study. The thermo-electric stimulator was modified so that commercially available components could be used. The modification consisted of: (1) the use of a machine tooled copper thermode rather than one made of cast silver; (2) the use of a stock thermocouple rather than one which was custom made; and (3) minor changes in the heat sink. Measurement of heat and cold is read directly on a Telethermometer" which is connected to a thermoster:* embedded in the stimulator tip. The machined copper stimulator is held in close physical contact with the face of the thermocouple by nylon screws and is ensheathed in a nylon sleeve to reduce heat exchange with the surrounding air (Figs. 1 and 2). The stock thermocouple*** draws

\footnotetext{
"Model \#42SC, manufactured by Yellow Springs Instrument $\mathrm{Co}$.

$\because$ Model \#4412, Cole-Parmer Instrument and Equipment $\mathrm{Co}$.

**Model \#507C634804, Westinghouse Corp.
}

Page 30/222 


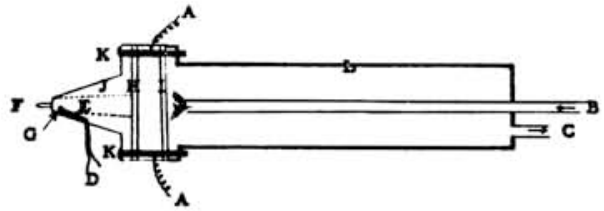

Fig. 1. Diagram of the thermo-electric tooth stimulator. (a) Electrical leads to the thermocouple. (b) Water intake. (c) Water exhaust. (d) Thermister leads. (e) Copper thermode. (f) Stimulator point. (g) Thermister probe. (h) Cold face of thermocouple. (i) Hot face of thermocouple. (j) Nylon sleeve. (k) Nylon as sembly screws. (1) Brass housing.

approximately 22 amperes of current for optimal cooling effect which antagonizes the Peltier cooling effect. A flow of current to the thermocouple in one direction cooled the stimulator tip from room temperature to $12^{\circ} \mathrm{C}$. By reversing the direction of current flow through the apparatus, the reversal of the thermal effect occurs and the tip is heated to $82^{\circ} \mathrm{C}$. Control of temperature is regulated by the magnitude of current. The degree of coldness possible to be produced depends not only on current magnitude, but also on the temperature of the water circulating in the system. The source of current for operation of the device is from a D. C. filtered power supply $* * ;$ which provides direct current output of 0-32 volts D. C. and 0-25 amperes D. C. with a 0.75 per cent maximum ripple.

A small device was developed for controlled application of mechanical stimuli to the cervical area of hypersensitive teeth Inc.

\#\#*\# Model \#NFB, Electro Products Laboratories,

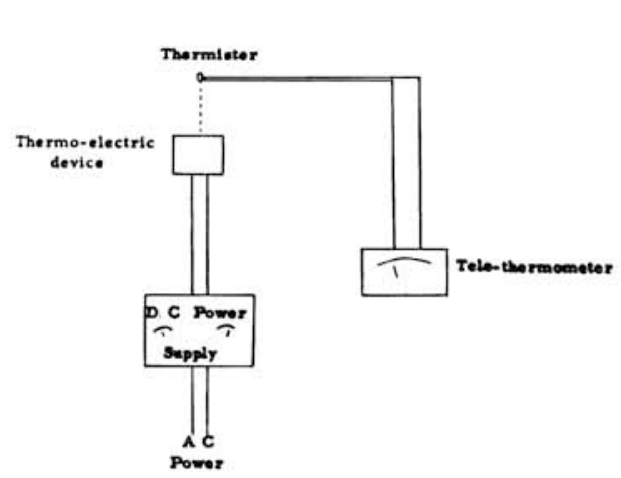

Fig. 2. Thermo-electric tooth stimulator system.

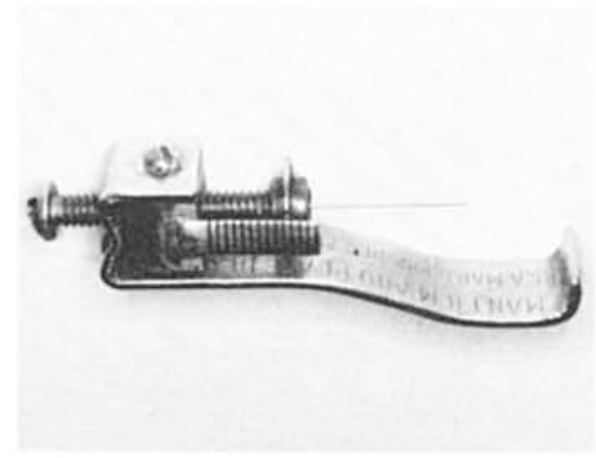

Fig. 3. Mechanical stimulating device.

(Fig. 3). The device was designed so that the point of a stainless steel wire, 15 millimeters in length (.026 ga.), could be swept in a small arc across the surface of a tooth. The lateral scratching force applied to the surface could be increased or decreased by rotation of a small adjustment screw. By moving the tip (which could subtend a small arc in lateral movement) beyond the highest arc of curvature of the tooth surface, greater scratching forces were produced. In effect, it was necessary for the spring wire to bend in order to pass across the surface of the tooth. The force applied was directly related to the amount of bending of the wire, and the amount of bending was directly proportional to the difference between the arc subtended by the tip of the stimulator wire and the highest point of curvature of the tooth. This difference was measured in one-quarter millimeters on a modified vernier scale on the device, and

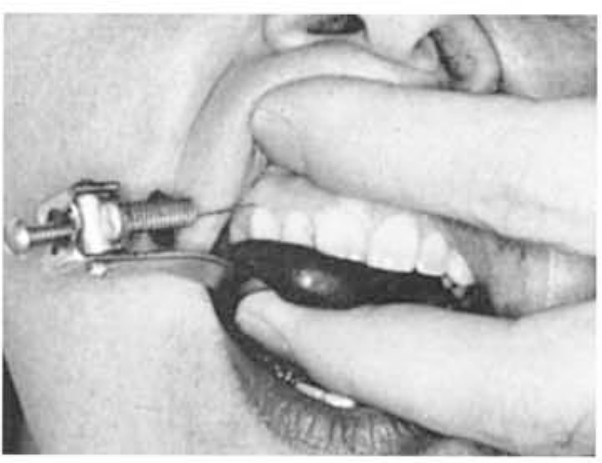

Fig. 4. Mechanical stimulating device and compound matrix in position for testing cervical
sensitivity. 
considered hereafter to be scratching force expressed in millimeters. Lateral movement of the stimulating point was made possible by mounting the stimulating wire and calibrated scale on a swivel pin attached to the stabilizing frame. The end of the stimulator wire was ground to a fine point to provide the stimulating tip. A compound matrix was fashioned to fit over the lingual and occlusal surfaces of three or four teeth in the area of a specific sensitive tooth. The end of the stabilizing frame of the mechanical stimulating device was pressed into the softened compound matrix so that the stimulating point would contact the root surface at the area of sensitivity (Fig. 4). This method of relating the point of the mechanical stimulator to the sensitive area gave a positive, reproducible relationship between the stimulating point and the tooth, and could be used for all subsequent measurements of mechanical stimulation.

The dentifrices to be evaluated were Sensodyne and its placebo.* According to information supplied by the manufacturer, the active dentifrice and its placebo contained the following ingredients:

\begin{tabular}{lr} 
Sensodyne: & \\
Strontium chloride $\cdot 6 \mathrm{H}_{2} \mathrm{O}$ & $10.00 \%$ \\
Deionized water & $36.80 \%$ \\
Polyols & $24.00 \%$ \\
Water-soluble gums & $1.80 \%$ \\
Anionic detergent & $1.70 \%$ \\
Nonionic detergent & $0.50 \%$ \\
Diatomaceous silica & $23.00 \%$ \\
Flavor and saccharin & $1.35 \%$ \\
Inert coloring agents & $0.75 \%$ \\
Preservative & $0.10 \%$ \\
\hline & $100.00 \%$ \\
Placebo of Sensodyne: & \\
Deionized water & $42.50 \%$ \\
Polyols & $26.70 \%$ \\
Water-soluble gums & $1.80 \%$ \\
Anionic detergent & $1.70 \%$ \\
Nonionic detergent & $0.50 \%$ \\
Diatomaceous silica & $24.50 \%$ \\
Flavor and saccharin & $1.45 \%$ \\
Inert coloring agents & $0.75 \%$ \\
Preservative & $0.10 \%$ \\
& $100.00 \%$ \\
\hline
\end{tabular}

\footnotetext{
"Supplied by Block Drug Co., Jersey City, New
} Jersey.
Toothbrushes (Py-co-pay, 2 row hard natural bristle) were supplied for the study by the manufacturer of the dentifrice being evaluated.*

A total of 20 subjects with hypersensitive teeth, five males and 15 females (range, 18-59, mean, 42.8, median, 37), were utilized in the investigation. All were selected from the clinic at the School of Dentistry, The University of Michigan. No attempt was made to select equal numbers of males and females or to select subjects on the basis of age. While it would have been desirable to have equal numbers of males and females, and a uniform age distribution of subjects, there was not a sufficient number of subjects with hypersensitive teeth available to meet this desire because of the restrictions imposed by the criteria for the selection of subjects in this study. The criteria for selection of subjects were: (1) a history of hypersensitivity to heat, cold, sweet, or mechanical stimuli; (2) no history of any type of dental therapy for at least one month prior to beginning of test ( 0 day); (3) no active dental therapy was to be undertaken during the period of testing; (4) no previous treatment of any type for hypersensitivity during the preceding six months prior to 0 day; (5) all areas of hypersensitivity to be tested had to exist on the facial surfaces of the teeth; (6) no subjects with active cervical caries were to be included in the study; and (7) the subject's desire to participate in the study for a period of 60 days. Subjects with cervical restorations were not excluded from the study provided testing could be accomplished without touching the restoration with the testing device.

A questionnaire was used to obtain the following information: age, sex, occupation, status of pregnancy, history and duration of bruxism, previous periodontal therapy, previous history of onset, duration, treatment, and cause of hypersensi-

\footnotetext{
"Supplied by Block Drug Co., Jersey City, New Jersey.
} 


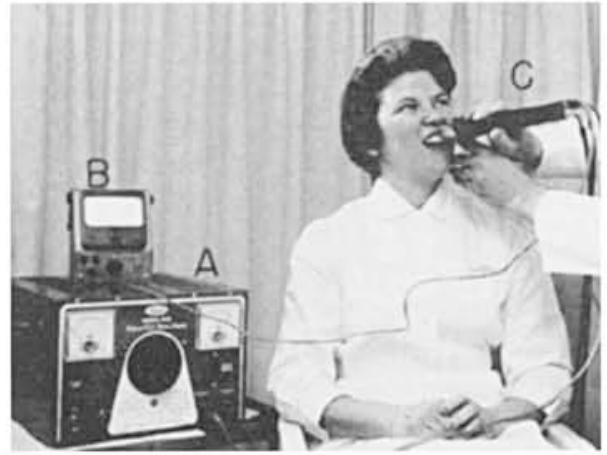

Fig. 5. Thermo-electric tooth stimulator system : (a) D. C. power supply. (b) Tele-thermometer (c) Thermo-electric tooth stimulator.

tivity (such as hot, cold, sweet, or mechanical stimuli), and the teeth which were sensitive. Before comparable groups could be formed, it was necessary also to determine each subject's impression of hypersensitivity and their reaction to quantitatively applied experimental stimuli. The information from the questionnaire and the results of the subject's reaction to the quantitatively applied experimental stimulus were used to form comparable groups to test Sensodyne against its placebo.

In order to avoid bias on the part of the investigator and subject, a so-called "double-blind" technic was used in this study. The active dentifrice and placebo were packaged in identical tubes, labeled by the manufacturer with a coded letter only. An ample supply of both active dentifrice and placebo was supplied by the manufacturer so that each subject could have as many tubes as requested. The code was withheld from the investigator and subjects by a disinterested third party until all testing was completed.

\section{CLINICAL PROCEDURES}

At the initial appointment the subjects were given the questionnaire and the compound matrix was made for the mechanical stimulating device.

On three subsequent visits, one week apart, the teeth previously recorded on the questionnaire as being sensitive were tested for their degree of sensitivity to mechanical

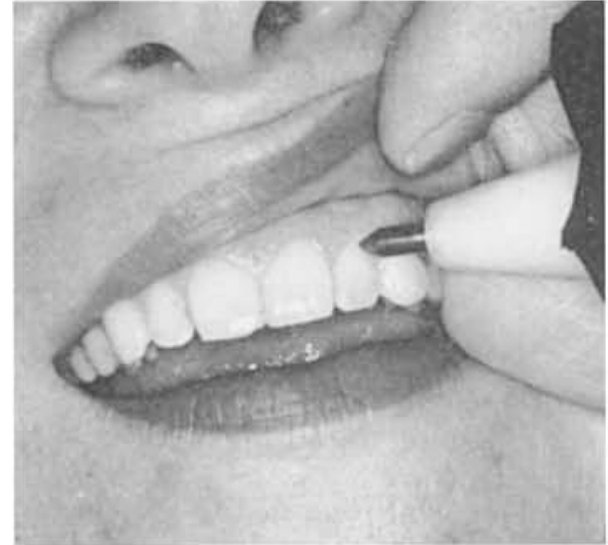

Fig. 6. Thermo-electric tooth stimulator.

stimulation, to cold, and to heat. The teeth were tested in the same order and the stimuli were applied in the same order on each visit, i.e., mechanical, cold, and then heat stimulation.

The procedure for measuring the degree of sensitivity to the mechanical stimulus was as follows: The compound matrix, previously fitted to the teeth at the initial appointment, was carefully placed in position on the teeth. The mechanical stimulating device was then carefully placed into its keyed position in the compound matrix, making sure the stimulating tip did not contact the tooth before testing began. The small adjustment screw of the stimulating device was rotated until the stimulating tip barely contacted the root surface (Fig. 4). Then the stimulating tip was moved across the area of sensitivity of the root. This procedure was repeated with increased pressure against the sensitive surface until the subject was just aware of pain. At this point the instrument was moved and the scratching force expressed in millimeters was read directly from the graduated scale on the device.

Sensitivity to cold was measured in the following manner: All testing began with the temperature of the stimulator tip at $37.5^{\circ} \mathrm{C}$. as indicated by the Tele-thermometer. The area of the sensitive tooth to be tested was wiped free of excess saliva, and the stimulator tip was placed lightly in 
contact with the root surface (Figs. 5 and 6). The temperature of the stimulator tip was slowly reduced in small increments of approximately $1^{\circ} \mathrm{C}$. When the stimulator tip reached each lower increment of temperature, the instrument was shut off and the stimulator tip was placed in contact with the root surface. The subjects were instructed to notify the investigator with a raise of the hand when pain was first ascertainable. At this point the temperature was read directly from the Telethermometer and recorded. This procedure was carried out for all sensitive teeth in the mouth.

Sensitivity to heat was measured in exactly the same manner as sensitivity to cold was measured, except the temperature of the stimulating tip was increased in small increments of approximately $1^{\circ} \mathrm{C}$. from the initial temperature of $37.5^{\circ} \mathrm{C}$. to the point where pain was felt by the subject.

At the completion of the three initial scorings, two groups of 10 subjects each were formed on the basis of forming groups as previously indicated. The groups were designated as Sensodyne D and Sensodyne B. The subjects in each group were given coded tubes of dentifrice; thus, 10 subjects received Sensodyne D dentifrice and 10 subjects received Sensodyne B. All subjects were given three new toothbrushes, advised to use their own brushing technic, and to brush as many times a day as they had in the past. The only stipulation made was that they brush at least once a day with the dentifrice which was furnished them. All the subjects were informed that the dentifrice they were going to use was for the purpose of reducing hypersensitivity. The beginning of the use of the dentifrice was considered to be 0 day in this study.

After use of the dentifrices for 30 days, the subjects were evaluated for changes in sensitivity. First the subjects were asked if there had been any change in the sensitivity of their teeth. Then, areas of sensitivity were tested using the mechanical and the thermal devices. The investigator did not refer to prior results of stimulation at any time during the study. Furthermore, the subjects were not told what results were being obtained during the study.

The code was broken by the disinterested third party at the end of 30 days for the purpose of identifying the active dentifrice. This was accomplished so that an active dentifrice would be used by all subjects during the last 30 days of the study, and thereby provide greater between group and within group comparisons. The code letter on the tubes was removed by the disinterested third party so the investigator or the subject would not know what dentifrice had been used during the previous 30 days. After 30 days on the active dentifrice, the subject returned and was again asked to give a subjective evaluation of his sensitivity status. The same procedure used for evaluating the degree of sensitivity to mechanical and thermal stimuli after the first 30 day period of the study was again used.

\section{STATISTICAL METHODS}

After groups were tentatively formed on the basis of information obtained from the questionnaire, the mean scores of thermal sensitivity, obtained in the initial testing procedures, were statistically analyzed for the purpose of determining whether or not the groups were statistically comparable.

To derive the mean scores for thermal sensitivity, the scores for all teeth quantitatively stimulated with cold were added together and the sum was divided by the number of teeth scored. To obtain the mean score of a group, all individual means were added and the sum was divided by the number of individuals scored. The same procedure was followed to obtain an individual and group mean score for teeth quantitatively stimulated with heat.

After completion of the final scoring for all subjects, data obtained at the 0,30 , and 60 day testing periods were statistically analyzed. Mean scores obtained from quantitative thermal stimulation of the teeth 
were analyzed by utilizing the following formulae:

$$
\begin{aligned}
\text { S.D. } & =\frac{\overline{N\left(\Sigma X^{2}\right)-(\Sigma X)^{2}}}{N} \\
\text { S.E. } & =\frac{\text { S.D. }}{\bar{N}} \\
t & =\frac{\overline{X_{1}}-\overline{X_{2}}}{\left(\bar{S} \cdot \overline{E_{\cdot 1}}\right)^{2}+(\overline{S \cdot E \cdot 2})^{2}}
\end{aligned}
$$

Deviations from the mean differences of 30 day scores obtained by mechanical stimulation were derived by: (1) subtracting the individual 30 day score from the individual mean of the three initial scores; (2) adding the differences of these scores and dividing the sum by the total number of subjects tested (thus giving the mean of the differences); and (3) subtracting the 30 day score from the mean difference (giving the deviation from the mean difference). The same procedure was followed to find the deviation from the mean differences for the 60 day scores obtained by mechanical stimulation.

It was necessary to utilize mean difference scores because there was no absolute baseline for mechaniacl stimulation. In other words, the mechanical stimulator was not constructed so the scale could be set at 0 to compensate for variations in thickness of teeth.

All evaluations of differences of means were based on $t$ scores at the 1 per cent level of confidence.

\section{RESULTS}

After the groups were tentatively formed on the basis of the data from the questionnaire, the mean scores obtained by thermal stimulation were analyzed for between group differences. The mean, standard deviation, standard error of the mean, and the results of Student's $t$ test for the groups are shown in Table I.

The results of breaking the code indicated that Sensodyne $D$ was the active dentifrice, and Sensodyne B was the placebo. The analysis of the differences of mean thermal scores between Sensodyne group D and Sensodyne group B at 0, 30, and 60 days is shown in Table II.

The analysis of within group differences of mean thermal scores of Sensodyne group $D$ and Sensodyne group B, between 0 and 30 and between 0 and 60 days, is shown in Table III.

Analysis of data obtained by mechanical stimulation is shown in Table IV. The standard deviation of the differences between 0 and 30 and between 0 and 60 days; the standard error of the mean difference; the difference of the mean difference; and results of the $t$ test are shown in the Table.

Results of the comparison of the subjective evaluation of the subject with objective evaluation of thermal sensitivity at 30 and 60 days are shown in Tables VA and VB.

Results of the comparison of the mean sensitivity of subjects with and without a history of gingivectomy are shown in Table VI. A comparison is arranged in Table VI to show differences in sensitivity between Sensodyne group D and Sensodyne group $B$ at 0,30 , and 60 days.

\section{DISCUSSION}

Although it was hoped that some correlation between the information obtained from the questionnaire and cervical sensitivity might be found, no apparent relationship was noted. However, the questionnaire was of value in forming groups of subjects with comparable subjective complaints.

Results of Student's $t$ test shown in Table I indicate that both groups (Sensodyne D and Sensodyne B) were statistically equivalent for sensitivity to heat and cold. It can be concluded that both groups were comparable in regards to thermal sensitivity prior to use of active Sensodyne and its placebo.

The analysis of between group differ- 
ences indicates that no alteration of sensitivity occurred after 30 and 60 days' use of the active Sensodyne or its placebo at the 1 per cent level of confidence. Thus, it can be concluded that active Sensodyne was no more effective in reducing cervical hypersensitivity of the teeth than a placebo.

The results of analysis of within group differences as shown in Table III indicate that there was no statistically significant change in sensitivity of the teeth to thermal stimulation after the use of Sensodyne D or Sensodyne B (placebo) for 30 or 60 days. It can be concluded that there

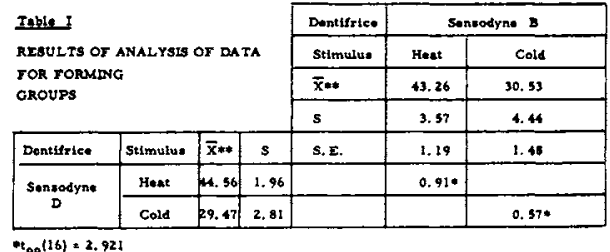

nemear of lastial 3 scoren in ${ }^{\circ} \mathrm{C}$.

was no statistically significant change in sensitivity after the use of Sensodyne or its placebo for 30 or 60 days.

An analysis of the results of mechanical stimulation as shown in Table IV indicates that there was no significant differences of

Table II

ANALYSLS OF DITTERENCES HETWEEN BENBODYNE GROUP D AND BENSODYNE GROUP B

\begin{tabular}{|c|c|c|c|c|c|c|c|c|c|c|c|c|}
\hline & \multirow{2}{*}{$\begin{array}{l}n \\
\bar{x} \neq *\end{array}$} & \multirow{2}{*}{$\frac{9}{43.43}$} & \multirow{2}{*}{$\frac{9}{30.52}$} & \multirow{2}{*}{$\frac{9}{44.03}$} & \multirow{2}{*}{$\frac{9}{31.28}$} & \multirow{2}{*}{$\frac{9}{46.25}$} & \multirow{2}{*}{29.01} \\
\hline & & & & & & & & & & & & \\
\hline & & & & & & s & 3.57 & 4. 34 & 4.79 & 3.89 & 5.36 & 4.17 \\
\hline $\begin{array}{l}\text { Denti- } \\
\text { Irice }\end{array}$ & Time & $s_{1} \lim _{4}$ & $\mathrm{n}$ & $\bar{x}^{* * *}$ & $s$ & $s E_{\bar{x}}$ & 1.19 & 1.45 & 1.60 & 1.30 & 1.85 & 1. 39 \\
\hline \multirow{2}{*}{$\begin{array}{l}\text { Senso- } \\
\text { dyne D }\end{array}$} & \multirow{2}{*}{$\begin{array}{c}0 \\
\text { Day }\end{array}$} & Hoat & 9 & 13.91 & 2.08 & 0.69 & $0.35 *$ & & & & & \\
\hline & & Cold & 9 & 29.67 & 3.21 & 1.07 & & $0.48 *$ & & & & \\
\hline \multirow{2}{*}{$\begin{array}{l}\text { Senso- } \\
\text { dyne D }\end{array}$} & \multirow{2}{*}{$\begin{array}{c}30 \\
\text { Days }\end{array}$} & Heat & 9 & 43.77 & 2. 86 & 0.95 & & & 0.14 & & & \\
\hline & & Cold & 9 & 29.22 & 2.82 & 0.94 & & & & 1.28 स & & \\
\hline \multirow{2}{*}{$\begin{array}{l}\text { Senso- } \\
\text { d;ne D }\end{array}$} & \multirow{2}{*}{$\begin{array}{c}60 \\
\text { Day }\end{array}$} & Heat & 9 & 14.04 & 2.71 & 0.90 & & & & & 1.074 & \\
\hline & & Cold & 9 & 29.49 & 3.18 & 1.06 & & & & & & $0.28^{\circ}$ \\
\hline
\end{tabular}
"If $(16)=2.921$ mean in ${ }^{\circ} \mathrm{C}$.

Table in

ANALYBLS OY GROUP DIFYERENCES WITHIN BENSODYNE GROUP D AND BENBODYNE GROUP B

(Thermal Stimulation)

\begin{tabular}{|c|c|c|c|c|c|c|c|c|c|c|c|c|c|c|}
\hline \multirow{2}{*}{\multicolumn{6}{|c|}{ (Thermal Stimulation) }} & & & & & & & & & \\
\hline & & & & & & $\mathbf{n}$ & 9 & 9. & 9 & 9 & 9 & 9 & 9 & 9 \\
\hline & & & & & & - & 2. 86 & 2.82 & 2.71 & 3.18 & 4.79 & 3.89 & 3.36 & 4.17 \\
\hline $\begin{array}{l}\text { Dents- } \\
\text { frice }\end{array}$ & Tlme & Sflmu & $\mathrm{n}$ & $\bar{x} * *$ &. & $S E_{\bar{x}}$ & 0.95 & 0.94 & 0.90 & 1.06 & 1.60 & 1.30 & 1.85 & 1. 39 \\
\hline Senuo- & 0 & Heat & 9 & 43. 91 & 2.08 & 0.69 & 0.13 & & 0.11 & & & & & \\
\hline & & Cold & 9 & 29.67 & 3.21 & 1.07 & & $0.32 *$ & & 0.12 & & & & \\
\hline Senso- & 0 & Heat & 9 & 43.43 & 3.57 & 1.19 & & & & & 0.30 & & 1.28 & \\
\hline dyne B & Day & Cold & 9 & 30.52 & 4. 34 & 1.45 & & & & & & 0.39 & & $0.7 \mathrm{~s}$ \\
\hline
\end{tabular}

*t29 (8) $=3.355$ 
Table IV

ANALYSIS OF MECHANICAL STIMULATION

\begin{tabular}{|c|c|c|c|c|c|c|c|}
\hline & & & & Time & 0.60 Day & 0-60 Daye & $0-30$ Daya \\
\hline & & & & $x^{2}$ & 0.811 & 0.744 & 0.320 \\
\hline & & & & $s$ & 0.320 & 0.270 & 0.180 \\
\hline Dentifrice & Time & $x^{2}$ & $s$ & SE & 0.106 & 0.086 & 0.034 \\
\hline $\begin{array}{c}\text { Senoodyne } \\
\text { D }\end{array}$ & 0-30 Daye & 0.454 & 0.24 & 0.079 & 1. 4694 & & 0.293 \\
\hline $\begin{array}{c}\text { Sensodyne } \\
\text { B }\end{array}$ & 0-30 Day & 0.320 & 0.18 & 0.054 & & $0.030 \%$ & \\
\hline $\begin{array}{c}\text { Senuodyne } \\
D\end{array}$ & 0-60 Day & 0.811 & 0.32 & 0.106 & & 1.60644 & \\
\hline
\end{tabular}

$x^{2}=$ the sum of the deviations of individual differences from the mean difference - squared.

$$
\begin{aligned}
& \text { At }(8)=3.355 \\
& \sin _{99}(16)=2.921
\end{aligned}
$$

the mean differences within and between Sensodyne group D and Sensodyne group B. Thus, there was no statistically significant alteration of sensitivity to mechanical stimulation after the use of Sensodyne $D$ and Sensodyne B (placebo) for 30 and 60 days.

The evaluation of the subject's impression of a change in sensitivity with the actual change in sensitivity, as indicated by differences in thermal sensitivity obtained by the investigator at 0 and 30 days
(Table VA), and at 0 and 60 days (Table $\mathrm{VB})$, shows some degree of correlation existed. As indicated in Table VA, no change in sensitivity was noted by 11 subjects after 30 days' use of Sensodyne or placebo. In these subjects no significant change to quantitative thermal stimuli was observed. No change in sensitivity was noted in seven subjects at the end of 60 days. Following the use of Sensodyne B (placebo) for 30 days, one subject out

Table VA

SUBJECTIVE AND OBJECTIVE EVALUATION OF SENSITIVITY

\begin{tabular}{|c|c|c|c|c|c|}
\hline \multirow{2}{*}{$\begin{array}{c}\text { Subject's Evaluation } \\
\text { of Change }\end{array}$} & \multirow[b]{2}{*}{$\mathbf{n}$} & \multirow[b]{2}{*}{ Stimulue } & \multicolumn{2}{|c|}{$\begin{array}{c}\text { Mean Thermal Scores } \\
\text { in }{ }^{\circ} \mathrm{C}\end{array}$} & \multirow{2}{*}{$\begin{array}{l}\text { Actual Moan Chango } \\
\text { in Sonoltivity } \\
\text { in }{ }^{\circ} \mathrm{C}\end{array}$} \\
\hline & & & O Day & 30 Deys & \\
\hline \multirow{2}{*}{$\begin{array}{l}\text { No change in } \\
\text { sencitivity }\end{array}$} & 11 & Heat & 43.65 & 44.09 & 0.44 (D.S.) \\
\hline & 11 & Cold & 30.13 & 30.52 & 0.19 (I. S.) \\
\hline \multirow{2}{*}{$\begin{array}{l}\text { Senoitlvity } \\
\text { increased }\end{array}$} & 1 & Heat & 41.50 & 40.50 & $1.00(1$. s.) \\
\hline & 1 & Cold & 30.00 & 31.50 & 1. 50 (I. S.) \\
\hline \multirow{2}{*}{$\begin{array}{l}\text { Senaltivity } \\
\text { decreased }\end{array}$} & 6 & Heat & 44.15 & 44.07 & 0.08 (I. s.) \\
\hline & 6 & Cold & 30.00 & 29.90 & 0.10 (D. S.) \\
\hline
\end{tabular}

D. S. = Decreaced sensitivity

1. S. = Increased sensitivity 
Table VB

BUBJECTIVE AND OBJECTIVE EVALUATION OF SENSITIVITY

\begin{tabular}{|c|c|c|c|c|c|}
\hline \multirow{2}{*}{$\begin{array}{c}\text { Subject's Evaluation } \\
\text { of Change }\end{array}$} & \multirow[b]{2}{*}{$n$} & \multirow[b]{2}{*}{ Stimulu: } & \multicolumn{2}{|c|}{$\begin{array}{l}\text { Mean Thermal Scored } \\
\text { in }{ }^{\circ} \mathrm{C}\end{array}$} & \multirow{2}{*}{$\begin{array}{l}\text { Actual Mean Change } \\
\text { in Seneitivity } \\
\text { in }{ }^{\circ} \mathrm{C}\end{array}$} \\
\hline & & & 0 Day & 60 Days & \\
\hline \multirow{2}{*}{$\begin{array}{l}\text { No change in } \\
\text { conaltivity }\end{array}$} & 7 & Heat & 44.61 & 45.74 & $1.13(D$. S.) \\
\hline & 7 & Cold & 28.53 & 28.88 & $0.35(1.5)$. \\
\hline \multirow{2}{*}{$\begin{array}{l}\text { Seneitivity } \\
\text { Increaced }\end{array}$} & 1 & Heat & 47.25 & 45.00 & 2.25 (1. 5.) \\
\hline & 1 & Cold & 27.00 & 24.50 & 3. 50 (D.S.) \\
\hline \multirow{2}{*}{$\begin{array}{l}\text { Senuitivity } \\
\text { decreased }\end{array}$} & 10 & Heat & 42.71 & 44.75 & $2.04 *(D .5)$. \\
\hline & 10 & Cold & 31.36 & 29.95 & 1.41 (D.S.) \\
\hline
\end{tabular}

D. S. = Decreased aensitivity

I. S. = Increased seneitivity

* $t=1.31$

$t_{99}(10)=3.25$

Table $\mathbf{V I}$

COMPARISON OF MEAN SENSITIVITY IN ${ }^{\circ} \mathrm{C}$ OF SUBJECTS WITH AND WITHOUT A HISTORY OF GINGIVECTOMY

\begin{tabular}{|c|c|c|c|c|c|c|c|c|c|}
\hline & & \multicolumn{4}{|c|}{ Gingivectomy Group } & \multicolumn{3}{c|}{ Non-gingivectomy Group } \\
\cline { 2 - 10 } Dentifrice & Stimulus & $\mathrm{n}$ & O Day & 30 Daya & 60 Days & $\mathrm{n}$ & 0 Day & 30 Days & 60 Days \\
\hline $\begin{array}{c}\text { Senoodyne } \\
\text { D }\end{array}$ & Heat & 3 & 43.38 & 42.04 & 42.33 & 6 & 44.28 & 44.63 & 44.89 \\
\cline { 2 - 10 } & Cold & 3 & 30.56 & 30.03 & 30.49 & 6 & 29.14 & 28.42 & 28.99 \\
\hline $\begin{array}{c}\text { Sensodyne } \\
\text { B }\end{array}$ & Heat & 6 & 44.35 & 44.84 & 45.98 & 3 & 41.58 & 42.08 & 46.79 \\
\hline
\end{tabular}

of a total of nine gave the impression of decreased sensitivity. This was interpreted as a possible placebo effect. The small actual mean changes in sensitivity shown in the last column of Table VA and VB are not statistically significant and do not corroborate the subjects' impressions of changes in sensitivity.

Table VI, which compares mean thermal sensitivity of subjects with and without a history of gingivectomy, does not show any significant differences in these two groups. A total of nine subjects with a history of gingivectomy had thermal sensitivity, while a total of nine subjects had thermal sensitivity without gingivectomy. Thus the occurrence of sensitivity in sub- jects having a history of gingivectomy does not differ appreciably from those subjects having root exposure due to other reasons.

\section{SUMMARY}

A double-blind study utilizing quantitatively applied thermal and mechanical stimuli was undertaken to investigate the effectiveness of Sensodyne dentifrice in reducing cervical hypersensitivity. A total of 20 subjects were used for this investigation. The active dentifrices were used for 60 days by a total of 10 subjects, while the placebo was used for 30 days by 10 subjects, after which time these same subjects used the active dentifrice for 30 days. Change in cervical sensitivity was measured 
at 30 and 60 days by a thermo-electric tooth stimulator and by a mechanical stimulating device.

\section{CONCLUSIONS}

There is no significant alteration of cervical hypersensitivity to mechanical stimuli after the use of Sensodyne for 30 or 60 days.

There is no significant alteration of cervical hypersensitivity to thermal stimuli after the use of Sensodyne for 30 or 60 days.

There is no significant correlation between subject's impression of change in sensitivity and actual change in sensitivity determined by application of quantitative stimuli.

\section{BIBLIOGRAPHY}

1. Abel, Irwin. Study of hypersensitive teeth and a new therapeutic aid. Oral Surg., Oral Med. and Oral Path. 11:491-5, May 1958.

2. Anderson, D. J., Curwen, M. P., and Howard, L. V. The sensitivity of human dentin. J. Dent. Res. 37:669-77, Aug. 1958.

3. Ayers, D., Jr., and Agate, F. J., Jr. Measurement of mechanical stimuli producing pain when applied to dentin. Internat. A. Dent. Res. Abstr. 35:112-3, 1957.

4. Bibby, B. G., and Hoyt, W. H. Fluorine therapy in dentin desensitization. J. Dent. Res. 22:208, 1943.

5. Bodecker, C. F. Clinical research on cause and treatment of cervical erosion-abrasion. Am. Dent. A. J. 1:105, Dec. 1942.

6. Bradford, E. W. Problem of the sensitivity of dentine. Dent. Pract. and Dent. Rec. 1:42-50, Sept. 1950.

7. Buckley, J. P. Practical therapeutics (sensitive dentine). Dental Review. 18:315-8, 1904.

8. Burman, L. R., and Goldstein, Abraham. Evaluation of a desensitizing agent by response to a controlled external stimulus. J. Periodont. 32:25760, July 1961.

9. Colaneri, J. N. Simple treatment of hypersensitive cervical dentin. Oral Surg., Oral Med. and Oral Path. 5:276-8, March 1952.

10. Clement, A. J. Sodium flouride paste as a desensitizing agent for hypersensitive dentin. Brit. Dent. J. 82:168, Apr. 1947.
11. Cohen, Abram. Preliminary study of the effects of a strontium chloride dentifrice for the control of hypersensitive teeth. Oral Surg., Oral Med. and Oral Path. 14:1046-52, Sept. 1961.

12. Eisenberg, M. J. Treatment of enamel and cemental hypersensitiveness with nacent silver iodine. Austral. J. Dent. 8:134, 1927.

13. Espeland, S. M., Jr. Study of pulp sensitivity resulting from foods and beverages. Dent. Students' Mag. 34:13-15, 52, March 1956.

14. Fitzgerald, Gerald. A clinical evaluation of a new agent for the relief of hypersensitive dentine. Dent. Digest. 62:494-7, Nov. 1956.

15. Grossman, L. I. A systematic method for the treatment of hypersensitive dentin. J.A.D.A. 22:592-602, Apr. 1935 .

16. Gysi, A. An explanation of the sensitivity of dentin. Dent. Cosmos. 43:68-9, 1901. Abstr.

17. Howard, L. V. Sensitivity in dentin. J. Dent. Res. 36:814, Oct. 1957, Abstr.

18. Jensen, S. B. Treatment of hypersensitive dentin with Argentozinc. Dent. Abstr. 1:183-4, March 1956.

19. Kramer, I. R. H. Relationship between dentin sensitivity and movements in the contents of the dentinal tubules. Brit. Dent. J. 98:391-2, June 1955.

20. Massler, Maury. Desensitization of cervical cementum and dentin by sodium silicofluoride. J. Dent. Res. 34:761-2, Oct. 1955.

21. McKenzie, J. S., and Mann, A. W. Treatment of sensitive cervical areas of teeth with hot olive oil applications. Oral Surg., Oral Med. and Oral Path. $2: 1558,1949$.

22. Naylor, M. N. A thermo-electric tooth stimulator. Brit. Dent. J. 110:228-30, Apr. 1961.

23. Pawlowska, J. Strontium chloride-its importance in dentistry and prophylaxis. Gzasopismo Stomatologiczne (J. Stomatol., Warsaw, Poland). 9:353, 1956.

24. Ross, M. R. Hypersensitive teeth: Effect of strontium chloride in a compatible dentifrice. J. Periodont. 32:49-53, Jan. 1961.

25. Rovelstad, G. H. Condition of the young dental pulp after the application of sodium fluoride to dentin. Northwest. Univ. Bul. 48:6-8, Nov. 1947.

26. Skurnik, Harry. Control of dental hypersensitivity. Preliminary report on a strontium-containing dentifrice. J. Periodont. 34:183-5, March 1963.

27. Sorensen, F. M., Phatak, N. M., and Everett, F. G. Thermal pulp tester: A new instrument. J. Dent. Res. 41:961-5, Sept.-Oct. 1962.

28. Toto, P. D., Staffileno, Harry, and Gargiulo, A. W. A clinical evaluation of a desensitizing toothpaste. J. Periodont. 29:192-4, July 1958. 